\title{
Long-term results of a balloon-assisted endoscopic approach in failed dacryocystorhinostomies
}

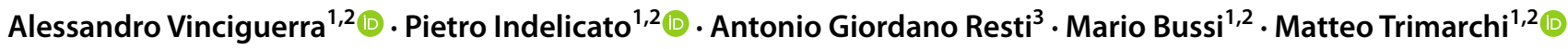

Received: 31 May 2021 / Accepted: 28 June 2021 / Published online: 12 July 2021

(c) The Author(s), under exclusive licence to Springer-Verlag GmbH Germany, part of Springer Nature 2021

\begin{abstract}
Purpose Endoscopic endonasal balloon-assisted dacryoplasty is a minimally invasive surgical approach that can be applied after failure of dacryocystorhinostomy with recurrence of distal acquired lacrimal obstruction.

Methods At the Department of Otolaryngology, San Raffaele Hospital, Milan (Italy), from December 2016 to October 2020, 14 patients underwent trans-nasal balloon-assisted dacryoplasty after a failed dacryocystorhinostomy (both external and endoscopic endonasal). The routinary pre-operative work-up included multidisciplinary study of the lacrimal disease, which consisted in primary ophthalmological and otorhinolaryngological visits associated with nasal endoscopy, in which a radiological exam was added if needed. The surgical approach includes pneumatic enlargement of the stenotic rhinostomy, created during the primary dacryocystorhinostomy, using a high-pressure trans-nasal balloon catheter. Anatomical success was considered when the ostium was patent upon irrigation, while functional success was considered as resolution of epiphora or free lacrimal flow on functional test.

Results Among 14 patients included and after a mean follow-up of 19.5 months (range 13-51 months), anatomic success was achieved in $100 \%$ of patients and functional success was achieved in the $85.7 \%$ (12/14). Operative time ranged from 9 to $28 \mathrm{~min}$ (mean $18 \mathrm{~min}$ ) and no complications were reported.

Conclusion Trans-nasal balloon-assisted dacryoplasty is a mini-invasive surgical approach to treat failed dacryocystorhinostomies with reliable and stable outcomes in the long term. The absence of post-surgical complications, high success rate and short operative time are the main features of this innovative procedure.
\end{abstract}

Keywords Dacryocystorhinostomy $\cdot$ Ballooning $\cdot$ Balloon dacryoplasty $\cdot$ Nasolacrimal duct obstruction $\cdot$ Revision surgery

\section{Introduction}

Distal acquired lacrimal obstruction (DALO) is a common pathology that affects the lacrimal drainage system distal to Rosenmuller's valve and its main clinical presentation is

Alessandro Vinciguerra and Matteo Trimarchi equally contributed as first author.

Matteo Trimarchi

trimarchi.matteo@hsr.it

1 Division of Head and Neck Department, Otorhinolaryngology Unit, IRCCS San Raffaele Scientific Institute, Milano, Italy

2 School of Medicine, Vita-Salute San Raffaele University, Milano, Italy

3 Division of Head and Neck Department, Ophtalmologic Unit, IRCCS San Raffaele Scientific Institute, Milano, Italy represented by epiphora or recurrent dacryocystitis [1]. The main etiology for this entity is believed to be idiopathic, also known as primary acquired nasolacrimal duct obstruction (PANDO), even if other causes have been described [2-9].

While in the past decades the approach of choice has been considered external dacryocystorhinostomy (EXTDCR) [10], a recent review has highlighted that, among all treatments available, endoscopic endonasal dacryocystorhinostomy (END-DCR), similar to EXT-DCR, is associated with higher functional success rates compared to other approaches; accordingly, both can be considered the gold standard techniques for DALO $[11,12]$. Nevertheless, it is generally acknowledged that END-DCR provides advantages over EXT-DCR, such as less operative time, morbidity, post-operative complications, and absence of external scar, which, however, frequently presents optimal esthetic outcomes [13-15]. 
Overall, END-DCR and EXT-DCR have a surgical failure rate of $10 \%$ that can be distinguished as early failure, mainly caused by inadequate surgery, or late failure, which can have multifactorial causes. In particular, the most common reasons for unsuccessful DCRs are excessive cicatricial ostium closure or granulation tissue formation, inadequate osteotomy/sac opening, internal ostium stenosis, common canalicular obstruction and sump syndrome [16]. Excluding the last two reasons, which require specific ophthalmological management, the others determine intranasal ostium stenosis which is mainly treated either with an endoscopic or external approach [17]. However, even if no significant difference has been noted, over the past few years, the END-DCR has

Table 1 Characteristics of the 14 patients included in the study

\begin{tabular}{lc}
\hline Patient characteristics & Total $(\%)$ \\
\hline Age & \\
$\geq 60$ y & $8(57)$ \\
$<60$ y & $6(43)$ \\
Gender & \\
Male & $1(7)$ \\
Female & $13(93)$ \\
Affected eye & \\
Left & $7(50)$ \\
Right & $7(50)$ \\
Previous surgery & \\
EXT-DCR & $4(29)$ \\
END-DCR & $10(71)$ \\
Time between 1st and 2nd surgery (months) & $7(50)$ \\
$<12$ & $4(29)$ \\
$\geq 12-24<$ & $3(21)$ \\
$\geq 24$ &
\end{tabular}

gained popularity among clinicians for revision surgeries because, using endoscopic instrumentation, it provides a direct identification of the cause for the surgical failure and permits its rectification [18]. In addition, several endoscopic mini-invasive approaches have been proposed, with particular attention to balloon-assisted endoscopic dacryoplasty (balloon END-DCP), which is a high-pressure balloon catheter system introduced through the nose and used to restore the lacrimal pathway in revision cases of distal acquired obstruction [19]. In fact, although a trans-canalicular balloon-assisted approach has been previously described, its potential damage to the canalicular system has limited its application in favor of endoscopic approaches [20].

The aim of this study is to analyze the long-term outcomes of our series of patients who underwent balloonassisted endoscopic dacryoplasty as revision surgery for recurrence of distal acquired lacrimal obstruction (Table 1).

\section{Methods}

In this analysis, we included patients who underwent, at the Department of Otolaryngology of San Raffaele Hospital in Milan (Italy), between December 2016 and October 2020, endonasal endoscopic balloon dacryoplasty (balloon ENDDCP) after a failed EXT-DCR or END-DCR.

All patients presented recurrent epiphora due to distal acquired lacrimal obstruction after a primary DCR (both END or EXT) and received a diagnosis on the site of obstruction made by multidisciplinary agreement between an otolaryngologist and ophthalmologist. In particular, the diagnostic work-up for failed dacryocystorhinostomy (Fig. 1) is initially based on ophthalmologic examination that differentiates canalicular disease or pump failure, which is
Fig. 1 Diagnostic work-up for failed DCRs. DCR: dacryocystorhinostomy; END-DCR: endoscopic endonasal dacryocystorhinostomy; CT: computed tomography

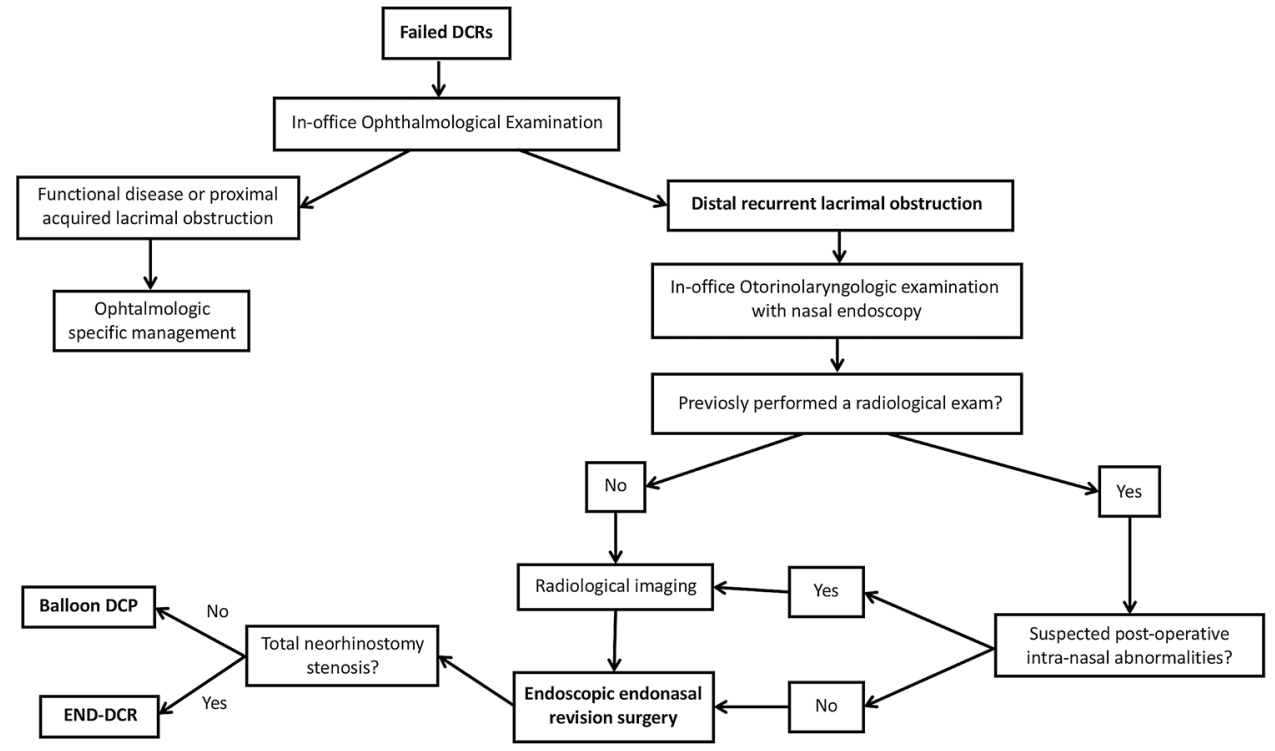


treated accordingly by an ophthalmologist, to distal recurrent obstruction. In fact, when a neorhinostomy closure is detected, in-office otorhinolaryngologic examination with $30^{\circ}$ rigid nasal endoscopes is mandatory to directly visualize the nasal cavities and to better define the potential cause of the surgical failure. Pre-operative radiological imaging, particularly maxilla-facial CT scan, was not always requested since in our END-DCR series, we always performed it before the primary approach to treat any possible nasal comorbidity during the primary surgery [21]. However, in case of suspected novel nasal pathologies or absence of radiological examination, particularly after an EXT-DCR for which it is not always requested, a pre-operative radiological imaging (MRI or CT) was performed to detect and treat any endonasal pathology that could have influenced the final outcome. When complete examination of the nasal-lacrimal condition was achieved, two different surgical techniques were proposed, standard END-DCR or endonasal endoscopic balloon-assisted dacryoplasty, depending on the endonasal characteristics. In particular, the applicability of balloon END-DCP has been standardized in patients with internal ostium stenosis with a tiny neorhinostomy highlighted on high-pressure lacrimal irrigation and visualized on nasal endoscopy; additionally, the procedure was proposed if no adjunctive endonasal procedures were needed.

All primary surgeries of the patients were treated for idiopathic distal obstruction, also known as primary acquired nasolacrimal duct obstruction (PANDO).

Exclusion criteria included other causes of NLDO such as malignancy, bone disease, previous radiotherapy, Down's syndrome, sarcoidosis and granulomatosis with polyangiitis (GPA).

Informed consent was obtained from each patient for treatment and use of de-identified clinical data for study purposes. We obtained approval from the institutional review board (IRB) of San Raffaele Hospital for this clinical review study, which was conducted according to the ethical standards established in the 1964 Declaration of Helsinki, as revised in 2000.

\section{Surgical technique}

All procedures were performed by the same two surgeons, one ophthalmologist and one otolaryngologist (M.T. and G.R.A), under general anesthesia following our previous description of this surgical approach. Nasal cavities were treated with local oxymetazoline hydrochloride-soaked gauze; subsequently, the inferior lacrimal punctum was dilated by the ophthalmologist with a Bowman's lacrimal probe that was inserted into the canalicular system down the stenotic lacrimal ostium. The tip of this probe was used as a surgical guide to allow direct endonasal endoscopic visualization of the stenotic point. Using an endoscopic endonasal approach, an $8 \mathrm{~mm}$ balloon catheter was gently introduced into the closed nasal neorhinostomy created during the primary DCR. Subsequently, the catheter, connected to an inflation device, determines enlargement of the rhinostomy using a balloon system which was inflated to $12 \mathrm{~atm}$ $\left(1.216 \times 10^{6} \mathrm{~Pa}\right)$ for 3 cycles of at least $20 \mathrm{~s}$ each (Fig. 2).

No nasal packing was placed post-operative, although bicanalicular silicone stenting was placed in selected cases (2/14) of primary post-operative extensive fibrosis. All cases were prescribed oral antibiotics (amoxicillin + clavulanate), antibiotic-steroid eye drops for 7 days, periodic nasal washes, and use of local emollient ointment. Followup visits were done on days 1 and 7 , once a week for the first month, and then once a month for 3 months and every 6 months for 1 year, similar to our previous data on ENDDCR [14].

All post-surgical clinical visits consisted of a nasal endoscopy and lacrimal pathway irrigation (Figs. 3 and 4). Anatomical success was defined if a patent ostium on irrigation was achieved, whereas functional success was defined as absence of tearing symptoms (less than Munk 1) [22] and free lacrimal flow on functional test.

\section{Results}

A total of 14 patients (13 females and 1 male) underwent 14 balloon dilatations for recurrence of epiphora after a failed EXT-DCR or END-DCR, 50\% were left neorhinostomy closures and 50\% right closures (Table 1). Considering all the revision END-DCRs performed in our institution between December 2016 and October 2020, 41\% (14/34) were treated with the balloon dilation, whereas $59 \%$ were treated in a standard endoscopic approach due to total neorhinostomy closure and excessive fibrosis, previous radiotherapy, and concomitant sarcoidosis or granulomatosis with polyangiitis.

In the included patients of this paper, several causes of primary surgical failure were detected, which included development of sinonasal synechiae close to the neorhinostomy (9/14), formation of foreign body granuloma (3/14), and fibrosis formation (2/14). All patients treated did not report any antecedent or concomitant episodes of acute dacryocystitis. Mean age was 58.4 years (range 38-75 years) and the main comorbidities were hypertension $(n=4)$, glaucoma $(n=1)$, chronic kidney disease $(n=1)$, and aortic valve stenosis $(n=1)$. In four patients (29\%), a primary EXT-DCR was performed, while the remaining ten patients $(71 \%)$ underwent primary ENDDCR. The mean duration between primary and secondary surgical approach ranged from 3 to 48 months (mean 15.7 months), whereas the mean time to symptomatologic 

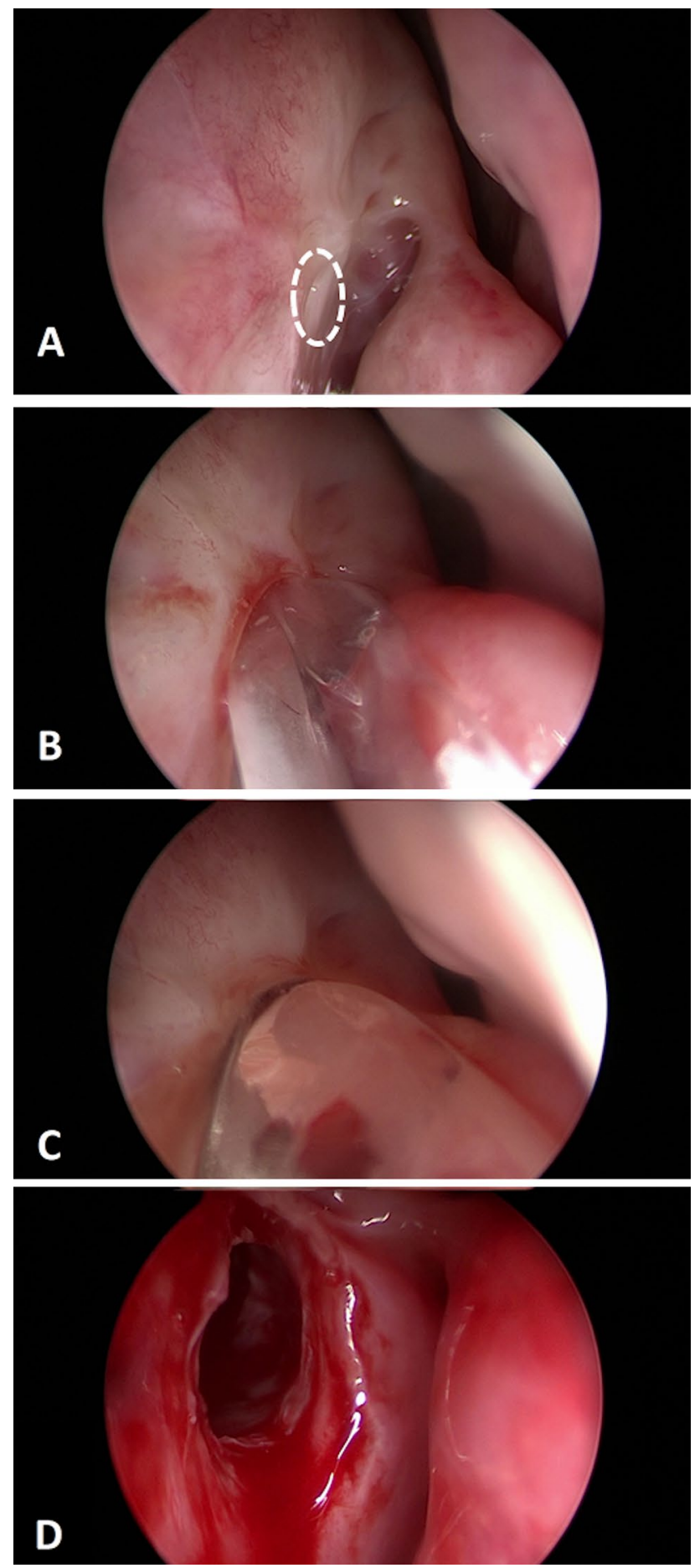

Fig. 2 Endoscopic endonasal balloon-DCP: A Stenotic neorhinostomy (dashed white circle); B Trans-nasal introduction of the balloon catheter into the stenotic neorhinostomy; C Complete inflation of the catheter; D Enlarged neorhinostomy

relapse was 6.5 months. All procedures were unilateral with a mean surgical duration of $18 \mathrm{~min}(9-28 \mathrm{~min})$; the mean follow-up length was 19.5 months (range 13-51 months).

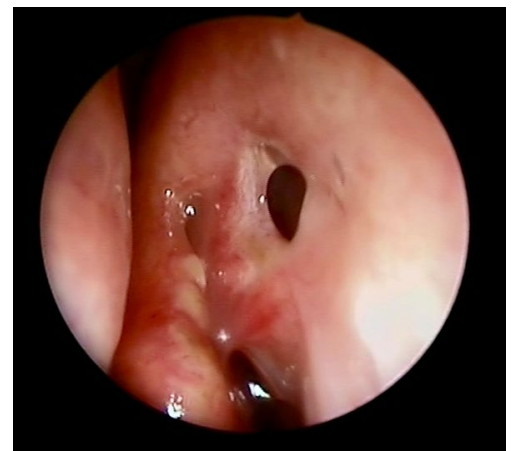

Fig. 3 Post-surgical follow-up: 28th post-operative day in patient A

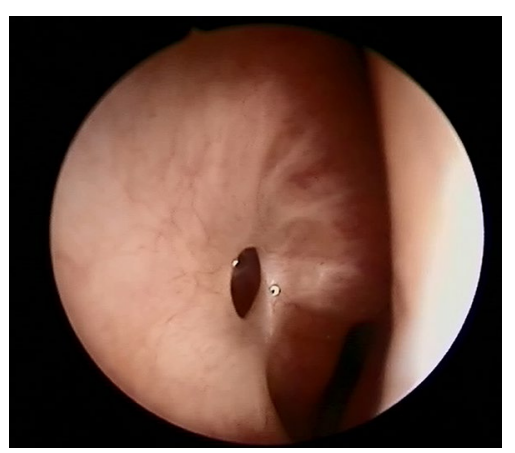

Fig. 4 Long-term post-operative follow-up: 12 months after surgery in patient $B$

At last follow-up, anatomic success rate was obtained in $100 \%$ of cases, whereas functional success was achieved in 85.7\% (12/14 patients). Among failed cases, recurrences were encountered within the first month and, to date, due to COVID-19 pandemic, no other treatment has been proposed. No significant complications such as bleeding, infection or bone necrosis were noted.

\section{Discussion}

END-DCR and EXT-DCR have recently gained the role of treatments of choice, as primary approaches, for DALO since they provide reliable and stable outcomes over the years [11]. Conversely, little is known about the best management for recurrent cases, which represent approximately $10 \%$ of treated patients.

To the best of our knowledge, this work represents one of the first studies analyzing long-term outcomes of balloon END-DCP and proposes a reproducible decision-making work-up for patients affected with recurrent distal acquired lacrimal obstruction after END-DCR or EXT-DCR (Fig. 1).

Revision surgeries for distal lacrimal obstruction is challenging for the oculoplastic and otorhinolaryngologic 
surgeon since several factors may concur and, not uncommonly, multiple causes for failure may be noted [16, 23]. In the last century, different approaches have been proposed, but external and endoscopic dacryocystorhinostomies still remain the treatments of choice; nevertheless, recent studies highlighted several advantages in revision cases of endoscopic approaches over the external one, rendering endonasal surgery more popular $[18,24,25]$. In fact, apart from the avoidance of a cutaneous scar and preservation of the orbicularis muscle, the endoscopic approach allows direct access to the stenotic lacrimal tract. This improves the possibility to address the specific cause of DCR failure and treat any concurrent pathologies which EXT-DCR may not allow [26]. As a result, more encouraging END-DCR outcomes have been reported compared to traditional external approach in revision surgeries [27, 28].

In recent years, a balloon-assisted dacryoplasty approach has been described for revision cases and represents a valid mini-invasive procedure in which a pneumatic force (the balloon catheter) determines an enlargement of the stenotic tract with no bone exposure and, consequently, less fibrosis or granulation tissue $[29,30]$. This innovative technical approach was first delivered through a trans-canalicular manner [31]. However, on one hand, this could cause potential canalicular damage due to manipulation of the proximal lacrimal drainage system [20], while on the other does not usually provide reliable outcomes compared to standard techniques [32]. As a result, an endoscopic endonasal balloon-assisted dacryoplasty has been described in few patients and applied either to revisions or primary cases, with encouraging outcomes: in fact, in this way the miniinvasive technique has been merged with direct visualization of the stenotic tract through endoscopic visualization and treatment $[32,33]$.

Our results demonstrate that, after mean follow-up of 19.5 months and no adverse events, balloon-END-DCP provides reliable and stable outcomes with anatomical success of $100 \%$ and functional success of $85.7 \%$, which is slightly decreased compared to our preliminary results at 6.4 months [19]. In fact, as demonstrated by Allon et al., a mean followup of 18 months is required to define the result as being stable for revision surgeries, since late neorhinostomy closure can occur [34]. Compared to our previous work, the present data represent the longest follow-up described for balloon END-DCP, with a functional success rate comparable to or even better than the long-term results of END-DCR revision cases. In particular, our previously reported revision ENDDCRs with a powered approach has demonstrated, among 96 patients, a functional success rate of $85.1 \%$ at mean follow-up of 38 months [14], whereas Ali et al. [27] described 23 cases of revision END-DCR with a mean follow-up of 26.4 months reporting an anatomical and functional success rates of $91.3 \%$ and $86.9 \%$, respectively, both data in line with our END-DCP results. Conversely, another revision END-DCR case-series made by Allon et al. [17] presented lower success, with yearly rates, from immediate to 5 years, of $93.3 \%, 75.5 \%, 71.1 \%, 68.9 \%, 68.9 \%$, and $68.9 \%$, respectively. Even if dichotomous compared to the work of Ali et al., the difference noted with the latter study can be explained by the less invasiveness and bone exposure of balloon END-DCP compared to standard END-DCR, which is also demonstrated by the reduced surgical time and the possibility to perform the balloon-END-DCP in local anesthesia [19]. Another reason for the lower surgical successes of Allon et al. can be explained by the long follow-up period and larger cohort size.

Nevertheless, it is noteworthy that the mini-invasive balloon END-DCP can be applied in a highly selected patients with subtotal internal ostium stenosis through which the balloon catheter can be placed and dilated in the lacrimal pathway; in fact, if a total neorhinostomy closure is detected, END-DCR should be considered the treatment of choice. However, one of the major drawbacks of this balloon device is the high equipment cost (140-170 euros for a powered approach vs 500-1200 euros for the balloon device), which could influence its applicability in lower-income countries.

Due to the limited number of publications on balloon END-DCP, comparison of our data with other similar studies is difficult. In fact, only Silbert et al. reported a success rate of $92 \%$ in 97 patients who underwent balloon END-DCP that, however, were treated as primary surgeries; in only 3 cases, it was subsequently applied as a revision technique, with success in only 1 of 3 patients. However, the difference of the technical primary surgery (END-DCR/EXT-DCR vs balloon END-DCP) makes these results incomparable.

Finally, considering post-surgical therapy, different possibilities have been discussed in the literature, both for postoperative medical therapy and bicanalicular stenting. Nevertheless, with the current data available regarding END-DCR, no difference is noted regarding either lacrimal stenting [34-36] or medical therapies (e.g., mitomycin C, oral antibiotics (ABT), nasal steroids or ocular steroids) [37-40]. As a result, in our series, we do not apply mitomycin $\mathrm{C}$, but we do prescribe post-operative oral ABT and antibiotic-steroid eye drops; bicanalicular stenting was placed in only selected patients (2/14) in which extensive fibrosis was noted as failure of the primary surgical approach.

The present study has some limitations: first, the retrospective design and the small number of patients involved are the main limitations of this study; second, the feasibility of balloon END-DCP depends on the dimension of the previous neorhinostomy so that complete stenosis makes the procedure more difficult to perform. As a result, the described outcomes could be hypothetically influenced by the selection bias of patients with favorable stenosis of the neorhinostomy. 


\section{Conclusion}

Considering revision surgeries after END-DCR and EXTDCR, balloon END-DCP is a mini-invasive procedure with reliable and stable outcomes in long-term that can be considered an option in patients with internal ostium stenosis. The reduced operatory time and absence of post-operative complications are the main advantages of this approach over revision DCRs. Future prospective studies are needed to compare balloon END-DCP to other surgical approaches in the management of recurrent distal lacrimal obstruction.

Author contributions AV and PI made substantial contributions to conception, design and acquisition of data, drafted the article and revised it critically for important intellectual content, gave final approval of the version to be published, and agreed to be accountable for all aspects of the work in ensuring that questions related to the accuracy or integrity of any part of the work are appropriately investigated and resolved; MT, AGR and MB made substantial contributions to conception of the data, revised it critically for important intellectual content, gave final approval of the version to be published, and agreed to be accountable for all aspects of the work in ensuring that questions related to the accuracy or integrity of any part of the work are appropriately investigated and resolved.

Funding This research received no specific grant from any funding agency in the public, commercial, or not-for-profit sectors.

Data availability Upon reasonable request.

\section{Declarations}

Conflict of interest None of the authors have any conflict of interest.

Ethical approval Approval was obtained from the ethics committee of the institutional review board (IRB) of San Raffaele Hospital for this clinical review study (April 2019), which was conducted according to the ethical standards established in the 1964 Declaration of Helsinki, as revised in 2000 .

Consent to participate and for publication Informed consent was obtained from each patient for treatment and use of de-identified clinical data for study purposes.

\section{References}

1. Ali MJ, Paulsen F (2019) Etiopathogenesis of primary acquired nasolacrimal duct obstruction: what we know and what we need to know. Ophthalmic Plast Reconstr Surg. https://doi.org/10.1097/ IOP.0000000000001310

2. Ali MJ (2016) Iodine-131 therapy and nasolacrimal duct obstructions: what we know and what we need to know. Ophthalmic Plast Reconstr Surg 32(4):243-248. https://doi.org/10.1097/IOP.00000 00000000647

3. Morassi ML, Trimarchi M, Nicolai P et al (2001) Cocaina, ANCA e granulomatosi di Wegener. Pathologica 93(5):581-583

4. Woog JJ (2007) The incidence of symptomatic acquired lacrimal outflow obstruction among residents of Olmsted County,
Minnesota, 1976-2000 (an American Ophthalmological Society thesis). Trans Am Ophthalmol Soc 105:649-666

5. Krishna Y, Coupland SE (2017) Lacrimal Sac Tumors-a review. Asia Pac J Ophthalmol. 6(2):173-178. https://doi.org/10.22608/ APO.201713

6. Ramberg I, Toft PB, Heegaard S (2020) Carcinomas of the lacrimal drainage system. Surv Ophthalmol 65(6):691-707. https:// doi.org/10.1016/j.survophthal.2020.04.001

7. Vinciguerra A, Rampi A, Giordano Resti A, Barbieri D, Bussi M, Trimarchi M (2021) Melanoma of the lacrimal drainage system: a systematic review. Head Neck. https://doi.org/10.1002/hed.26705

8. Trimarchi M, Bondi S, Della Torre E, Terreni MR, Bussi M (2017) Palate perforation differentiates cocaine-induced midline destructive lesions from granulomatosis with polyangiitis La perforazione del palato differenzia le lesioni destruenti della linea mediana indotte da cocaina dalla granulomatosi con poliangioite. ACTA Otorhinolaryngol Ital 37:281-285. https://doi.org/10. 14639/0392-100X-1586

9. Resti AG, Bertazzoni G, Trimarchi M (2013) Nasolacrimal duct obstruction secondary to dental impaction. Eur J Ophthalmol 24(4):611-613. https://doi.org/10.5301/ejo.5000410

10. Sobel RK, Aakalu VK, Wladis EJ, Bilyk JR, Yen MT, Mawn LA (2019) A comparison of endonasal dacryocystorhinostomy and external dacryocystorhinostomy: a report by the American Academy of Ophthalmology. Ophthalmology. https://doi.org/10. 1016/j.ophtha.2019.06.009

11. Vinciguerra A, Nonis A, Giordano Resti A, Bussi M, Trimarchi M (2020) Best treatments available for distal acquired lacrimal obstruction: a systematic review and meta-analysis. Clin Otolaryngol 45(4):545-557. https://doi.org/10.1111/coa.13551

12. Vinciguerra A, Nonis A, Resti AG, Barbieri D, Bussi M, Trimarchi M (2020) Influence of surgical techniques on endoscopic dacryocystorhinostomy: a systematic review and meta-analysis. Otolaryngol Head Neck Surg. https://doi.org/10.1177/0194599820 972677

13. Sharma V, Martin PA, Benger R et al (2005) Evaluation of the cosmetic significance of external dacryocystorhinostomy scars. Am J Ophthalmol 140(3):359.e1-359.e7. https://doi.org/10.1016/j. ajo.2005.11.061

14. Trimarchi M, Giordano Resti A, Vinciguerra A, Dane G, Bussi M (2019) Dacryocystorhinostomy: Evolution of endoscopic techniques after 498 cases. Eur J Ophthalmol. https://doi.org/10.1177/ 1120672119854582

15. Huang J, Malek J, Chin D et al (2014) Systematic review and meta-analysis on outcomes for endoscopic versus external dacryocystorhinostomy. Orbit 33(2):81-90. https://doi.org/10.3109/ 01676830.2013 .842253

16. Hull S, Lalchan SA, Olver JM (2013) Success rates in powered endonasal revision surgery for failed dacryocystorhinostomy in a tertiary referral center. Ophthalmic Plast Reconstr Surg 29:267271. https://doi.org/10.1097/IOP.0b013e3182916556

17. Allon R, Cohen O, Bavnik Y, Milstein A, Halperin D, Warman M (2020) Long-term outcomes for revision endoscopic dacryocystorhinostomy - the effect of the primary approach. Laryngoscope. https://doi.org/10.1002/lary.28795

18. Nair AG, Singh S, Kamal S, Ali MJ (2018) The importance of endoscopy in lacrimal surgery. Expert Rev Ophthalmol 13(5):257-265. https://doi.org/10.1080/17469899.2018.1520635

19. Indelicato P, Vinciguerra A, Giordano Resti A, Bussi M, Trimarchi M (2020) Endoscopic endonasal balloon-dacryoplasty in failed dacryocystorhinostomy. Eur J Ophthalmol. https://doi.org/ $10.1177 / 1120672120942692$

20. Mishra AK, Nilakantan A, Mishra S, Mallick A (2018) Comparison of balloon dacryocystorhinostomy with conventional endonasal endoscopic dacryocystorhinostomy for relief of acquired distal nasolacrimal drainage obstruction and its impact on quality of life: 
a prospective, randomized, controlled study. Med J Armed Forces India 74(3):255-263. https://doi.org/10.1016/j.mjafi.2017.08.010

21. Trimarchi M, Giordano Resti A, Bellini C, Forti M, Bussi M (2009) Anastomosis of nasal mucosal and lacrimal sac flaps in endoscopic dacryocystorhinostomy. Eur Arch Otorhinolaryngol 266(11):1747-1752. https://doi.org/10.1007/s00405-009-1002-z

22. Munk PL, Lin DT, Morris DC (1990) Epiphora: treatment by means of dacryocystoplasty with balloon dilation of the nasolacrimal drainage apparatus. Radiology 177:687-690. https://doi.org/ 10.1148/radiology.177.3.2243969

23. Welham RAN, Wulc AE (1987) Management of unsuccessful lacrimal surgery. Br J Ophthalmol 71(2):152-157. https://doi.org/10. 1136/bjo.71.2.152

24. Yarmohammadi ME, Ghasemi H, Jafari F, Izadi P, Nadoushan MJ, Chin NS (2016) Teamwork endoscopic endonasal surgery in failed external dacryocystorhinostomy. J Ophthalmic Vis Res 11(3):282-286. https://doi.org/10.4103/2008-322X.188396

25. AltinEkin M, KaradenizUgurlu S, Aytogan H, SahinAtik S (2020) Failure in revision dacryocystorhinostomy: a study of surgical technique and etiology. J Craniofac Surg 31(1):193-196. https:// doi.org/10.1097/SCS.0000000000005829

26. Orcutt JC, Hillel A, Weymuller EA (1990) Endoscopic repair of failed dacryocystorhinostomy. Ophthal Plast Reconstr Surg 6(3):197-202. https://doi.org/10.1097/00002341-19900 9000-00009

27. Ali MJ, Psaltis AJ, Wormald PJ (2014) Long-term outcomes in revision powered endoscopic dacryocystorhinostomy. Int Forum Allergy Rhinol 4(12):1016-1019. https://doi.org/10.1002/alr. 21398

28. Lehmann AE, Scangas GA, Jafari A, Banks CG, Fullerton ZH, Metson R (2020) Predictors of long-term success and failure in primary and revision endoscopic dacryocystorhinostomy. Int Forum Allergy Rhinol 10(3):374-380. https://doi.org/10.1002/ alr. 22483

29. Janssen AG, Mansour K, Krabbe GJ, Van Der Veen S, Helder AH (1994) Dacryocystoplasty: Treatment of epiphora by means of balloon dilation of the obstructed nasolacrimal duct system. Radiology 193(2):453-456. https://doi.org/10.1148/radiology. 193.2.7972762

30. Indelicato P, Vinciguerra A, Giordano Resti A, Trimarchi M (2020) A case of endonasal balloon-assisted dacryoplasty after failure of endonasal dacryocystorhinostomy. Clin Case Reports 8(9):1605-1609. https://doi.org/10.1002/ccr3.2956

31. Ali MJ, Naik MN, Honavar SG (2013) Balloon dacryoplasty: ushering the new and routine era in minimally invasive lacrimal surgeries. Int Ophthalmol 33(2):203-210. https://doi.org/10.1007/ s10792-012-9652-z
32. Lee BJ, Nelson CC, Lewis CD, Perry JD (2012) External dacryocystorhinostomy outcomes in sarcoidosis patients. Ophthal Plast Reconstr Surg 28(1):47-49. https://doi.org/10.1097/IOP.0b013 e3182364ad2

33. Silbert DI, Matta NS (2010) Outcomes of 9mm balloon-assisted endoscopic dacryocystorhinostomy: Retrospective review of 97 cases. Orbit 29(3):131-135. https://doi.org/10.3109/01676830. 2010.480924

34. Kim DH, Kim SI, Jin HJ, Kim S, Hwang SH (2018) The clinical efficacy of silicone stents for endoscopic dacryocystorhinostomy: a meta-analysis. Clin Exp Otorhinolaryngol 11(3):151-157. https://doi.org/10.21053/ceo.2017.01781

35. Kang MG, Shim WS, Shin DK, Kim JY, Lee JE, Jung HJ (2018) A systematic review of benefit of silicone intubation in endoscopic dacryocystorhinostomy. Clin Exp Otorhinolaryngol. 11(2):81-88. https://doi.org/10.21053/ceo.2018.00031

36. Ing EB, Bedi H, Hussain A et al (2018) Meta-analysis of randomized controlled trials in dacryocystorhinostomy with and without silicone intubation. Can J Ophthalmol 53(5):466-470. https:// doi.org/10.1016/j.jcjo.2017.12.006

37. Sousa TTS, Schellini SA, Meneghim RLFS, Cataneo AJM (2020) Intra-operative mitomycin-C as adjuvant therapy in external and endonasal dacryocystorhinostomy: systematic review and metaanalysis. Ophthalmol Ther 9(2):305-319. https://doi.org/10.1007/ s40123-020-00253-x

38. Nair AG, Ali MJ (2015) Mitomycin-C in dacryocystorhinostomy: From experimentation to implementation and the road ahead: a review. Indian J Ophthalmol 63(4):335-339. https://doi.org/10. 4103/0301-4738.158082

39. Phelps PO, Abariga SA, Cowling BJ, Selva D, Marcet MM (2020) Antimetabolites as an adjunct to dacryocystorhinostomy for nasolacrimal duct obstruction. Cochrane Database Syst Rev. https://doi. org/10.1002/14651858.CD012309.pub2

40. Vinciguerra A, Nonis A, Resti AG, Bussi M, Trimarchi M (2020) Impact of post-surgical therapies on endoscopic and external dacryocystorhinostomy: systematic review and meta-analysis. Am J Rhinol Allergy 34(6):846-856. https://doi.org/10.1177/19458 92420945218

Publisher's Note Springer Nature remains neutral with regard to jurisdictional claims in published maps and institutional affiliations. 